\title{
A Idéia de Sistema Jurídico e o Novo Código Civil: Contribuição ao desafio hermenêutico da aplicação do Direito
}

\author{
Antônio Maria Iserhard*
}

A idéia de sistema jurídico é a base de construção do próprio Direito. É sobre a noção de sistema jurídico que se dá a jurisdição, ou seja, a técnica de dizer o Direito, o que exige esforço hermenêutico, envolvendo interpretação, integração, correção e aplicação do Direito.

De maneira que a hermenêutica jurídica, ferramenta para o exercício da jurisdição, tem como ponto de partida uma visão sistemática do ordenamento jurídico.

Portanto, a concepção de sistema jurídico é pressuposto para o desenvolvimento do próprio Direito, de tal sorte que sistema jurídico e direito se identificam como se fossem a dupla face de Jano.

Para uma melhor noção do conceito de sistema jurídico, que se aplica a qualquer sistema, concorda-se que:
Há duas características que emergiram em todas as definições: a da ordenação e a da unidade; elas estão, uma para com a outra, na mais estreita relação de intercâmbio, mas são, no fundo, de separar. No que respeita, em primeiro lugar, à ordenação, pretende-se, com ela quando se recorra a uma formulação muito geral, para evitar qualquer restrição precipitada - exprimir um estado de coisas intrínseco racionalmente apreensível, isto é, fundado na realidade. No que toca à unidade, verifica-se que este factor modifica o que resulta já da ordenação, por não permitir uma dispersão numa multitude de singularidades desconexas, antes devendo deixá-las reconduzir-se a uns quantos princípios fundamentais.'

Quando se faz alusão ao sistema jurídico, logo se imagina a forma de pares binários, dualista, dicotômico e an-

\footnotetext{
* Doutor em Direito pela UFSC; professor no curso de Pós-Graduação da UNISC e na UCS; presidente da Escola Superior da OAB/RS.

1 CANARIS, Wilhelm Claus. Pensamento Sistemático e Conceito de Sistema na Ciência do Direito. 2. ed. Lisboa: Calouste, 1996. p.12-13.
} 
titético, tais como externo e interno; aberto e fechado; móvel e imóvel; dinâmico e estático.

Legado jusnaturalista, a concepção sistemática do direito tornou possível o surgimento das grandes codificações, erigidas a partir do início do século XIX.

Neste sentido, o primeiro código a aparecer foi o Código Civil Francês, também conhecido como código napoleônico, em 1804, o qual não só influenciou as demais codificações do continente ocidental, a exemplo do Código Civil Alemão, de 1900 e o Código Civil Brasileiro, de 1916, como também serviu de base para a edificação dos grandes sistemas de direito civil, dos sistemas de direito privado e dos grandes sistemas jurídicos contemporâneos do mundo ocidental.

Contudo, convém lembrar que o código napoleônico por ser fruto de uma revolução, cujo lema era liberdade, igualdade e fraternidade, procurou consubstanciar tais ideários jusnaturalistas, visando a proporcionar garantia, segurança e certeza nas relações jurídicas.

Assim, o Código Civil Francês apresentou-se como um código fechado, completo e acabado, como se fosse um bloco sem fendas, pois pretendiam os legisladores regrar todos os fatos da vida social, servindo de panacéia para a cura de todos os males.

De modo que não se pode descontextualizar a codificação civilista francesa de seu momento, eis que toda legislação é produto da sua própria historicidade cultural.

Anteriormente ao advento do Código Civil Francês, no regime feudal, vi- cejava uma justiça venal, em que havia juízes peitados e senhores feudais arvorando-se em juízes, decidindo os litígios invariavelmente em detrimento dos servos da gleba, alvo de combate da Revolução Francesa, visando a suplantar o reino de injustiça instalado no antigo regime.

Por isso, compreende-se que a codificação civilista francesa se apresentasse como um monumento jurídico que assegurasse e preservasse formalmente os direitos conquistados, a fim de que não se retornasse ao anterior regime.

Tal codificação, defendida pela escola exegética francesa, infundiu a crença da infalibilidade do legislador como se fosse um ser onisciente, onipresente e onipotente, capaz de prever todos os fatos que pudessem ocorrer na sociedade.

Estava aí lançada a semente no solo fértil do movimento exegético que se seguiu na França, com a escola exegética francesa, na Alemanha, com a escola dos pandectas e na Inglaterra, com a escola analítica.

O exegetismo é caracterizado pelo fetichismo legalista, emprego do método dedutivo e silogismo jurídico na solução dos conflitos sociais, tendo no texto legal o ponto de partida, do qual é deduzido logicamente a solução jurídica, através de um raciocínio subsuntivo do fato à regra jurídica, fórmula cômoda de solução dos conflitos sociais.

Do positivismo legalista ao normativismo jurídico kelseniano, forma extremada do positivismo jurídico, foi só questão de tempo. Apareceu, então, em 1934, a $1^{a}$ edição alemã da Teoria Pura do Direito, de Hans Kelsen, tentativa 
mais acabada de construção de uma Ciência do Direito, constituindo ainda hoje, o pensamento jurídico dominante no mundo ocidental.

Kelsen, com sua assepsia axiológica, legou ao mundo ocidental uma teoria do Direito sem o Direito, tal a purificação a que submeteu o conhecimento jurídico. Sua postura monista, ao identificar Estado, direito e lei, reduz o fenômeno social que é o Direito, ao puro juridismo. Apresenta o sistema jurídico como um sistema de normas, cujo fundamento e conteúdo de validade são deduzidos logicamente de uma norma fundamental, fictícia.

Um sistema de normas cujo fundamento de validade e conteúdo de validade são deduzidos de uma norma pressuposta como norma fundamental é um sistema estático de normas. ${ }^{2}$

Kelsen fecha o sistema jurídico a tal ponto de não admitir a existência de lacunas, pois o que não está proibido é juridicamente permitido pelo sistema normativo, elevando com sua postura gnosiológica o formalismo jurídico ao grau extremo de radicalização.

No entanto, não obstante as críticas dirigidas contra o exegetismo, desferidas pelo utilitarismo, teleologismo, sociologismo, livre investigação científica do direito, escola do direito livre e a própria escola histórica do direito, dentre outras, o positivismo jurídico seguiu seu curso, fazendo ouvidos moucos para as críticas que lhe foram endereçadas.
Durante sua travessia histórica, desde seu aparecimento com o Código Civil Francês, o positivismo jurídico não apresentou respostas para o problema das lacunas, da lei injusta, da contradição de princípios e dos conceitos indeterminados.

O positivismo, por seu turno, soçobra em quatro aspectos decisivos, todos eles reconhecidos. Em primeiro lugar, um positivismo cabal não admite - não pode admitir - a presença de lacunas. E quando, levado pela evidência, acabe por aceitá-las, não apresenta, para elas, qualquer solução material: a integração da lacuna - operação que, por excelência, exige o contributo máximo da Ciência do Direito - realizar-se-á, pois à margem do pensamento jurídico.

Um tanto na mesma linha, verifica-se, depois, que o positivismo não tem meios para lidar com conceitos indeterminados, com normas em branco e, em geral, com proposições carecidas de preenchimento com valorações: estas realidades, cada vez mais difundidas e utilizadas nos diversos setores do ordenamento, carecem, na verdade, de um tratamento que, por vezes, tem muito em comum com a integração das lacunas. $\mathrm{E}$ tal como nesta, também naquelas jus positum pode não oferecer soluções operativas: o positivismo cairá, então, no arbítrio do julgador.

Muito importante na crítica ao positivismo é a sua inoperacionalidade em situações de contradições de princípios. A possibilidade de tais contradições, há muito presente em ENGISCH, por exemplo, encontra-se equacionada na presente obra, por CANARIS, numa esquematização que não oferece dúvidas ou dificuldades. Ora, a postura metodológica

2 KELSEN, Hans. Teoria Pura do Direito. 5. ed. Coimbra: Armênio Amado, 1979. p. 270. 
juspositiva não pode, perante o fenômeno, senão negá-lo, ignorá-lo ou remeter a sua solução para os acasos das decisões subjetivas.

Finalmente, o juspositivismo detém-se perante a questão complexa mas inevitável das normas injustas. Desde logo, a idéia de "injustiça" duma norma regularmente produzida é de difícil - quiçá impossível - representação para as orientações que, do jus positum, tenham uma concepção auto-suficiente: falece uma bitola que viabilize o juízo de "injustiça". 3

O Código Civil Brasileiro, apresentava uma tábua sistemática de matérias, que era o retrato da sociedade agrária da época, expressada do modelo de estado liberal.

Na parte especial, tratava inicialmente Do Direito de Família, fundada no casamento legítimo, cujo vínculo é inviolável, tendo na figura do marido o chefe da sociedade familiar, com poder marital e pátrio poder. No livro II, cuidando $D o$ Direito das Coisas, marcado pela figura do proprietário, possuidor, dono de propriedade e titular de direitos reais sobre coisas alheias. O livro III, ao dispor Do Direito das Obrigações, destaca a imagem do contratante. Finaliza, com o tratamento Do Direito das Sucessões, no livro IV, onde destaca o testador.

Portanto, o código civil de 1916 é o estatuto do homem liberal.

Passados mais de 85 anos de vigência, surge um novo código civil, elaborado por uma comissão de juristas presidida pelo professor Miguel Reale, ini- ciando os trabalhos em 1969, há mais de 30 anos.

O novo código civil, Lei 10.406 , de 10/01/2002, em vigor desde 11 de janeiro do ano em curso, resulta de um projeto de lei que chegou à Câmara Federal no ano de 1975. Portanto, já nasce velho, traduzindo o fracasso da codificação, haja vista que fotografa o tempo passado, denunciando que o Direito não acompanha as mutações sociais.

Do encaminhamento do projeto à Câmara dos Deputados até sua publicação, muitos diplomas legislativos foram promulgados, tais como: a Lei do Divórcio, Lei 6.515, de 26/12/1977, o Estatuto da Criança e do Adolescente, Lei 8.069, de 13/07/1990, o Código de Defesa do Consumidor, Lei 8.078, de $11 / 09 / 1990$ e mais recentemente o Estatuto da Cidade, Lei 10.257 de 10/07/ 2001.

Por aí se vê a pletora legislativa produzida, não incorporada originariamente ao novo Código Civil, para não falar no direito ambiental, na bioética, no biodireito e no direito virtual.

Aliás, após a vigência do código civil ocorreu acentuada proliferação legislativa tanto em nível constitucional, com as constituições federais de 1934 , 1937, 1946, 1967, com emenda $n^{\circ} 1$ de 1969 e a magna carta de 1988, quanto infraconstitucional, como o Estatuto da Mulher Casada, Lei 4121 de 27/08/ 1962 e o Código de Processo Civil, Lei 5.869 , de $11 / 01 / 1973$.

3 CORDEIRO, A. MENEZES In: CANARIS, Wilhelm Claus. Pensamento Sistemático $e$ Conceito de Sistema na Ciência do Direito. 2.ed. Introdução e tradução A. Menezes Cordeiro. Lisboa: Calouste, 1996. p.xx - xxiii. 
Atentando-se para a estrutura do novo Código Civil verifica-se que, à exceção da introdução de um novo livro, intitulado Do Direito de Empresa, na parte especial, tentativa fracassada de procurar unificar o Direito das Obrigações Civil e Comercial, permanece a mesma do código revogado, porém alterando-se a disposição sistemática na ordem de apresentação dos demais livros desta parte especial.

De sorte que ao lado das figuras do marido, do proprietário, do contratante e do testador, aparece a do empresário. Tal inovação, trazida a respeito $D o D i$ reito de Empresa, lembra o liberalismo.

O que é mais problemático na admissão da existência de um direito da empresa é que este pode limitar inadmissivelmente a liberdade de comércio e de concorrência numa área não abrangida por normas especiais. ${ }^{4}$

Por isso mesmo, a expressão Direito de Empresa parece equivocada por não se coadunar com os novos rumos do sistema jurídico. Passou-se do Estado liberal para o Estado social.

A nova ordem constitucional sintetizada na magna carta de 1988, trouxe consigo a constitucionalização do Direito civil, e a exigência que o novo Código Civil seja o estatuto da pessoa humana, ao invés de continuar sendo o estatuto do homem, do indivíduo abstrato, coisificado, próprio do Código Civil antigo.
Mas, para isto não basta só mudar a legislação. É necessário mudar a mentalidade dos juristas, assumir nova postura hermenêutica frente aos conflitos, que não se cingem meramente aos interindividuais, mas que são cada dia mais transindividuais, difusos e coletivos.

A grande questão a desafiar a imaginação dos operadores do Direito, consiste na harmonização dos textos legislativos, pelo que reclamam uma visão interdisciplinar do fenômeno jurídico.

A segurança, a certeza e a garantia das relações jurídicas restaram liquidadas com o fim da modernidade, pela impossibilidade de se sustentar a existência de fórmulas prontas para a solução dos problemas sociais, cada vez mais complexos.

Urge repensar o sistema jurídico, cuja plenitude lógica não passa de um mito, não podendo funcionar como redutor da complexidade social.

Não há mais lugar para sistemas jurídicos fechados, homogêneos e herméticos no mundo globalizado. Vivenciamos uma cultura pós-moderna que atinge o próprio sistema jurídico, "caracterizada por quatro fenômenos: o pluralismo, a comunicação, a narratividade e o retorno aos sentimentos (retour aux sentiments), cujo leitmotiv seria o papel primordial dos direitos humanos". 5

O pluralismo das fontes normativas, de sujeitos, a comunicação, cujo tempo não mais se controla, a narrativida-

4 LEITÃo, Adelaide Menezes. Estudo de Direito Privado sobre a Cláusula Geral de Concorrência Desleal. Coimbra, Almedina, 2000. p. 126.

5 TEPEDINO, Gustavo. apud Jayme, Erick. Anais, v. I, XVII Conferência Nacional dos Advogados. Justiça e Utopia. Código Civil, os chamados microssistemas jurídicos e a constituição. Rio de Janeiro, UERJ, 1999, p. 191. 
de, face à existência de normas jurídicas que simplesmente dão uma certa diretiva e os direitos humanos, orientados pela dignidade da pessoa humana, estão a caracterizar a cultura pós-moderna, como apontou Erick Jayme.

Vive-se a era dos estatutos, em que determinados institutos, categorias e conceitos se independentizam do Código Civil, desenvolvendo-se em microssistemas, tal como ocorreu com o Estatuto da Mulher Casada, o Código de Defesa do Consumidor, o Estatuto da Criança e do Adolescente e mais recentemente o Estatuto da Cidade.

A proliferação destes diplomas legislativos, usurpando da codificação civilista determinados institutos, como ocorreu com a locação de serviços, regulada pela consolidação das leis do trabalho e com a locação de coisas, regrada pela lei de locações, nos sucessivos diplomas do inquilinato emergidos após o surgimento do Código Civil de 1916, dentre outros, caracterizam ofenômeno que se convencionou chamar de descodificação do Direito Civil.

Deste modo, a codificação civil vem experimentando sucessivo estilhaçamento, resultando enfraquecida sua previsibilidade normativa, pelo que outros textos legais quer constitucionais quer infra-constitucionais, devem ser cotejados na interpretação, integração, correção e aplicação do direito.

O juiz já não é mais a boca da lei, no dizer de Montesquieu, mas o criador do direito no caso concreto. Houve um deslocamento interpretativo, do legislador para o julgador.

Para a aplicação do direito já não são suficientes os parâmetros interpretati- vos antropomórficos da vontade do legislador ou animista da vontade da lei, mas impõem-se uma nova visão sistemática do direito.

Se nos primórdios do direito, a fonte jurídica eram os costumes, posteriormente a doutrina, que cedeu lugar ao primado da lei, com a positivação do direito. Hodiernamente, reside na própria interpretação, posto que todas as formas de expressão do jurídico são convocadas para dizer o direito.

Não tem lugar, hoje, para renovar o debate travado no século XIX, pelos juristas alemães Thibault e Savigny sobre a necessidade de codificação para o direito civil.

A questão não pode ser colocada em termos de codificação ou descodificação, sistematização ou assistematização, macrossistema ou microssistema, porquanto todos os textos legais devem ser chamados para o esclarecimento hermenêutico na aplicação do direito, que deve se travar na centralidade do caso. Não há mais lugar para posturas maniqueístas.

A previsão normativa cede terreno cada vez mais para os enunciados normativos, cuja narratividade importa em diretrizes para o julgador, que deve recorrer a valores, mesmo até fora do sistema jurídico, para integrar o direito numa perspectiva de harmonização de princípios e regras jurídicas, não raro conflitantes.

Há uma mudança de paradigmas que passa da centralidade do Código Civil para a centralidade do caso concreto. Pode-se dizer que ao lado dos conceitos indeterminados e da eclosão de conflitos de princípios constitucionais, proliferam o aparecimento de cláusulas gerais, a de- 
safiar a capacidade do julgador no provimento do direito de forma justa.

Segundo Guido Alpa,

as cláusulas gerais não representam nem princípios dedutivos nem princípios de argumentação dialética; trata-se de uma diretiva para a procura da norma de decisão, de uma técnica de formação judicial da regra a aplicar ao caso concreto, sem um modelo de decisão pré-constituído devido a uma factispecie abstrata. Identificar as cláusulas gerais com os princípios gerais é uma operação de aproximação que peca por defeito e por excesso. Entre conceito determinado e indeterminado há uma diferença de grau e não de espécie. Enquanto que entre conceitos indeterminados e cláusulas gerais há uma diferença de natureza. Os primeiros são indeterminados no plano ligüístico ao passo que as segundas são indeterminadas no plano dos valores. ${ }^{6}$

O novo Código Civil, além dos conceitos indeterminados de boa-fé, bons costumes, abuso de direito, eqüidade, falsa causa, falsidade, idoneidade, indignidade, injúria, juízo perfeito, justo motivo, caso fortuito, força maior, dentre outros, que perpassa todo o arcabouço civilista de Clóvis Bevilacqua, inova ainda com os institutos da lesão, do estado de perigo, da justa causa, do castigo imoderado, trazendo ainda as cláusulas gerais da função social do contrato e da função social da propriedade, respectivamente, em colisão com a autonomia da vontade e a propriedade absoluta.

Por consequiência, a diretriz trazida no novo arcabouço civilista está a orientar o julgador para a função social, conteúdo do direito de propriedade e do direito contratual, na aplicação do direito.

Por certo que haverá colisão de princípios, na aplicação do direito em muitas situações jurídicas, quando em confronto o direito de propriedade privada e sua função social, a autonomia da vontade e a função social do contrato, que por sua vez deverá ser solucionado levando-se em consideração o princípio da dignidade da pessoa humana, fundamento do Estado Democrático de Direito.

A nova codificação civilista procura refletir o Estado social, ao estabelecer a igualdade dos cônjuges e dos filhos.

A problemática hermenêutica consiste em como aplicar as cláusulas gerais na solução do caso concreto. Atente-se, por exemplo, para a resolução do contrato por onerosidade excessiva, para concretização da probidade e da boafé, na conclusão e execução do contrato, previstas no novo Código Civil.

Assiste-se, pois, com a chegada da nova codificação civil um alargamento ainda maior do espaço dos conceitos indeterminados.

Por conceito indeterminado entendemos um conceito cujo conteúdo e extensão são em larga medida incertos. Os conceitos absolutamente determinados são muito raroś no direito. ${ }^{?}$

A mudança experimentada no direito, passa de uma matriz positivista formal para um modelo positivo social,

6 LEITÃO. Estudo de Direito Privado... p. 122-123.

7 ENGISCH, Karl. Introdução ao Pensamento Jurídico. 3. ed.. Lisboa: Calouste, 1964. p. 173. 
afetando a própria idéia de sistema jurídico, pelo que:

o sistema não é, necessariamente, axiomático, fechado, completo e dedutivo, antes comportando todas as operaçòes que a moderna doutrina tem vindo a isolar. $\mathrm{O}$ pensamento sistemático em jogo é, em termos claros muito diferente do inicial. ${ }^{8}$

A idéia de sistema não pode ser rejeitada, pois a partir de sua base se edifica todo o direito. Urge, neste momento, enfrentar os problemas que o positivismo jurídico durante muito tempo escamoteou, principalmente dos conceitos indeterminados, agravados com o surgimento intensivo das cláusulas gerais, comprometendo a previsibilidade normativa do estatuto civilista.

O novo Código Civil mantém a parte geral com base na justificativa de reforçar a própria idéia de sistema, na medida em que está interligada com a parte especial.

Contudo, não pode a parte geral estruturar todo o sistema jurídico, sob pena de admitir-se que a partir dela se deduziriam logicamente as soluções para o contido na parte especial.

O Direito não é um sistema meramente dedutivo, é sim um sistema dialético, orientado ao problema, é uma recompilação de pontos de vista sobre o problema em permanente movimento; é aberto e pragmático. ${ }^{9}$

Os lidadores do Direito devem saber operar com os novos conceitos que per- meiam o novo Código Civil, a iniciar, na parte geral, com os conceitos de pessoa, que não é mais o do homem abstrato, de personalidade, bastante desenvolvido, de negócio jurídico, que não se confunde com o contrato.

É preciso ter presente ainda, que o simples aspecto de iniciar o tratamento da parte especial com a temática Das Obrigações, não significa prestígio ou desprestígio desta instituição em relação a outras dispostas na ordem seqüencial da disposição das demais instituições do novel diploma legislativo.

O que dá mobilidade ao sistema jurídico civil são as cláusulas gerais, funcionando como servidão de passagem do próprio sistema jurídico, por onde transitam os valores, mesmo os oriundos fora do Código Civil, voltados para os valores não patrimoniais.

As cláusulas gerais, por conterem a narrativa, as diretrizes e a comunicação para os operadores do Direito, servirão de balizamento para a sua aplicação, permitindo-lhes enfrentar a centralidade do caso, sem incorrer em mero casuísmo

O novo Código Civil, por sofrer os influxos da constitucionalização do direito privado, deve ancorar-se na hermenêutica constitucional. Porém, a lei, os costumes, a doutrina, a jurisprudência, os princípios gerais do direito, a analogia e a equiidade, devem ser convocadas a depor na grave missão de dizer o direito, tarefa que exige interpretação, integração, e correção, visando aplicar o direito justo.

8 CORDEIRO, A. MENEZES In: CANARIS, Pensamento Sistemático... p. 1xx.

9 LORENZETTI, Ricardo Luis. Fundamentos do Direito Privado. São Paulo: Revista dos Tribunais, 1998. p.80. 
Totalmente no começo estão ainda os esforços para a integração do antigo sistema do direito privado no conjunto da ordem jurídica actual. os aspectos elaborados e os problemas vitais ameaçam cada vez mais transplantar-se para a constituição social e para os direitos administrativo, econômico e social; a isto corresponde um certo despovoamento dos núcleos mais centrais do direito privado tradicional. Talvez este perigo seja evitado se a ciência do direito privado se aplicar sobretudo à preparação e elaboração sistemática daqueles problemas que hoje se formam nos terrenos marginais situados na linha divisória entre a conformação social e a proteção dos interesses privados - precisamente no domínio em que, de acordo com o que antes foi dito, residem também as questões materiais do seu destino. ${ }^{10}$

Tem-se, pois, que o grande desafio apresentado aos operadores do direito é a própria harmonização das fontes jurídicas, às quais se somam as cláusulas gerais infestando todo o sistema jurídico civilista e privado.

Não há mais lugar para catalogar casos, pois cada caso requer seja enfrentado na sua centralidade, exigindo do hermenêuta uma formação sóciocultural, técnico-jurídica, prático-profissional e ético-política.

Sendo assim, então para a ciência do Direito como também para a filosofia "prática" (quer dizer, a ética e a filosofia do Direito), a única espécie de sistema ainda possível é o sistema "aberto" e, até um certo grau, "móvel" em si, que nunca está completo e pode ser continuamente posto em questão, que torna clara a "racionalidade intríseca", os valores directivos e os princípios do Direito. ${ }^{11}$

Neste sentido, a fonte do direito passa a ser sua própria interpretação e seu limite passa a ser a ética.

\section{REFERÊNCIAS}

CANARIS, Claus Wilhelm. Pensamento Sistemático e Conceito de Sistema na Ciência do Direito. 2. ed. Lisboa: Calouste, 1996.

CÓDIGO Civil. 7. ed., São Paulo: Revista dos Tribunais, 2002.

CONSTITUIÇÃO da República Federativa do Brasil. 27. ed. São Paulo: Saraiva, 2001.

O NOVO Código Civil. São Paulo: Revista dos Tribunais, 2002.

ENGISCH. Karl. Introdução ao Pensamento Jurídico. 3. ed. Lisboa: Calouste, 1964.

KELSEN, Hans. Teoria Pura do Direito. 4. ed. Coimbra: Aménio Amado, 1979.

LARENZ, Karl. Metodologia da Ciência do Direito. 3. ed. Lisboa: Calouste, 1997.

LEITÃO. A'delaide Menezes. Estudo de Direito Privado Sobre a Cláusula Geral de Concorrência Desleal. Coimbra: Almedina, 2000.

LORENZETTI, Ricardo Luis. Fundamentos do Direito Privado. São Pau10: Revista dos Tribunais, 1998.

10 WIEACKER, Franz. História do Direito Privado Moderno. 2.ed. Lisboa: Calouste, 1967. p.722.

11 LARENZ, Karl. Metodologia da Ciência do Direito. 3.ed. Lisboa: Fundação Calouste Gulbenkian, 1997. p. 241. 
TEPEDINO, Gustavo. Justiça e Utopia: Código Civil, os chamados microssistemas jurídicos e a constituição. In: CONFERENCIA NACIONAL DOS ADVOGADOS, 17, 1999, Rio de Ja- neiro. Anais... Rio de Janeiro: UERJ, 1999.

WIEACKER, Franz. História do Direito Privado Moderno. 2.ed. Lisboa: Calouste, 1967. 